\title{
THE NATURE OF APPLIED PROBLEMS IN ALGEBRA.*
}

\author{
By David Eugene Smith, LL.D., \\ Professor of Mathematics in Teachers College, Columbia \\ University, New York.
}

TWO SCHOOLS OF MATHEMATICS.

From a time so remote as to deserve being designated as immemorial there have been two distinct schools of mathematicians. The first in point of time and numbers, though not of influence, is the school of practical mathematicians, the men who made our commercial arithmetic, settled our methods of computing, furnished our genuine problems in mensuration and mechanics, and used the mathematics of the theorists as far as they had need for them. The second school is that of the theorists, the dreamers in the science and the mystery of numbers, the logicians who built up our geometry, and the men who have posed or ranked, and now rank or pose, as original investigators. The smaller minds in each school have always affected to look down upon the minds of the other, but the larger minds have sought rather to appreciate to the full the thoughts and labors and aspirations and results of the masters in both fields. So Thales, who in times remote founded the science of geometry, was one of those who did not scorn to use that science for practical ends, and Archimedes of ancient Syracuse, and Heron of Alexandria, and Newton, Laplace, Lagrange, Kelvin, and Klein, are among the multitude of those who are imbued with the same all-embracing spirit.

In our day we are not free from the distinction, and the world will probably never break down the barrier. On the one side the inquiry will be raised, Cui Bono? What is mathematics good for? What are the genuine applications? And on the other side the dogma of mental discipline will be sounded forth from the minarets of the city, and the faithful will be admonished that utility is the aim of inferior intellects.

Now two such schools of thought cannot exist through the centuries without each having the support of truth. There is never continuity founded upon falsehood. Hence it comes that the world's best teachers have always sotght the truth in each

*A paper read at the December, I905, meeting of the New York State Science Teachers Association. 
of these schools. They have recognized the value of pure mathematics per se, but they have also recognized the value of the science as it has measured up in one way or another the quantitative side of human life.

Let us see, for example, what has been done in our day for arithmetic that we may estimate more clearly the possibilities for the reform along the higher lines of algebra.

THE QUESTION IN RELATION TO ARITHMETIC.

Now in arithmetic no considerable number of people seriously think of banishing the drill work with abstract numbers. The ability to work rapidly and accurately, developed by centering the thought on the operation itself and not on the interpretation of a problem, is considered vital. It is here that students are the most deficient when they enter college, and there is a just complaint in business that this phase of work is unduly neglected. On the other hand no one would think of having no concrete problems in which the pupils should translate a question into the language of number, and answer it in that language. The chief dispute of late has been as to the nature of these concrete problems. There are several possibilities for them:

(I) They may be mere puzzles, with no reference to practical life. Such puzzles are not without their value. They often arouse an interest through their very absurdity, as in the 7 cats killing 7 rats in 7 minutes, or through their evident impracticability, as in the pipes filling the cistern. But no one would advocate more than a few such problems, and common sense would suggest scattering them so as to recognize their peculiar value of enlivening the game that is being played in a mathematical course.

(2) They may be obsolete business problems as well as modern ones, on the principle that the reasoning involved is quite as good with unreal as with real examples. This would, of course, be a sound enough argument if it were not for the fact that it is innecessary to give false ideas of the business world about us. Since just as good reasoning can be obtained from genuine problems as from those that give a distorted idea of practical life, the latter become pernicious. Such are problems in equation of payments, partnership involving time, alligation, all of which have been banished from modern arithmetics.

(3) They may be genuine problems gleaned from the world 
about us, types of what the child is to meet, examples with an interesting and valuable content, questions that relate to the country's resources, to the daily life of our people, to the interests of the living rather than of the dead. All modern writers on arithmetic seek such problems, and it is only a matter of patience to find them in large supply. Such problems are sometimes criticised, but these criticisms will not deter their growth and extensive use with all text-book makers and all modern teachers. They are here to stay.

THE QUESTION IN RELATION TO ALGEBRA.

Now how is it with our algebra? Are the conditions similar to those of arithmetic? Have we an inherited mass of problems as open to criticism as the conglomeration of arithmetical examples that have come down to us in considerable measure from the $\mathrm{r}_{5}$ th century? In other words, are there types to be considered corresponding to those already mentioned in arithmetic?

(I) What about the abstract work? It is not in the province of this paper to elaborate this topic. But briefly it may be asserted as probably not open to serious objection that there must be the same mechanical efficiency here as in arithmetic, and this better comes from manipulating a large number of abstract functions than from solving a smaller number of concrete problems. Facility, certainty, accuracy in this work is indispensable to all higher analysis and applied mathematics. This must, therefore, stand about as now, save that we might better the sequence, merely eliminating absurd concatenations that are never met, and substituting forms that are common in later work.

(2) What shall be done with the puzzles? My hope is that they may be retained within reason, simply for the amusement and interest that attach to them. If their value in this line is recognized, they are not open to objection. No student considers very seriously a problem about finding a number. which increased by a seventh of itself equals ig (historically the oldest problem involving a linear equation that has come down to us). It is interesting, it furnishes some valuable exercise, and as a type it is unobjectionable if used in moderation.

(3) But what is the outlook for genuine problems? Can we regenerate algebra as we have regenerated arithmetic? Is there a field in which algebra is really used, and which at the same time 
is one that the pupil is prepared to enter? Can we touch life with the equation, tell any of the story of humanity with the formula, and give to a function a genuine social content? If we cannot vitalize algebra would it not be better to reduce it in quantity, with the confession that its mere educational value does not warrant, and that advanced mathematics does not need, the expenditure of a year and a half of a pupil's time in the manipulation of abstract and seemingly useless functions?

Personally I am an optimist here as elsewhere. I believe that if we search out uses for algebra, aside from the uses of the subject in higher studies, we shall find them. While I am forced to admit that we do not have a large number now, I believe it is because we have hardly begun to look for them. Twenty years ago a genuine American problem in arithmetic was somewhat of a rarity; people said it was necessary to preserve the inheritance because we had nothing as good to substitute; but today, authors are finding plenty of genuine applications, and they find them simply becatse they look for them.

THE POSSIBILITIES FOR ALGEBRA.

Now what are the possible fields for algebra? In the first place there is the formula, the most natural of all introductions to algebra. Instead of having a pupil begin by manipulating a lot of meaningless functions, it is perfectly feasible to let him see at least one use of algebra by beginning with genuine formulas. Happily the field is here a fertile one. The artisan's journals furnish many illustrations, the business rules of arithmetic furnish others, and elementary science supplies still more. Opposed as I am to turning our classes in mathematics into classes in physics, I am still aware that every child entering the high school knows enough of natural laws to appreciate formulas on the lever and on uniform motion. Formulas embodying the most common cases in general percentage, in interest, and in discount are not only easily understood by children, but they illustrate one of the chief uses of the algebra of which they are beginning the study. Hence there is abundant material of this kind for the first steps in the new science, material that is interesting, that is valuable, that is related to human life and that is practical for the artisan, the merchant, and the business man generally. Once the interest in such formulas is aroused, this interest will help to hold the pupil to his work in the fundamental 
operations with abstract functions. But I am not without hope that even in the latter field a line of applications will be found, just as we find this line in arithmetic on the one hand and calculus on the other.

The next field of applications that has proved fertile thus far is related to the negative number. Instead of approaching this subject from the abstract side, or with the help of the single illustration of debt and credit, we now have abundant material of which the teacher can take advantage. Chronology, latitude, longitude, temperature, assets, games, the numbering of east and .west streets, opposed forces, and many other similar lines of practical applications make the negative number seem as real and usable today as the positive.

The linear equation with one unknown also offers abundant practical material. One has only to seek and he finds. Percentage problems are particularly valuable in showing the practical uses of the linear equations, although the field is by no means limited to this group of applications. I should therefore look with suspicion on any algebra which should appear today without a considerable number of honest business problems under this head, problems that are interesting, valuable, informational, and as full of mental discipline as the old inheritances that have come down to us through the middle ages.

In the study of ratios, with those particular. subtopics known as proportion and variation, we have an abundance of applications that are of the best type of excellence; problems with a genuine content, but not involving technicalities beyond the understanding of the pupil.

When we come to linear equations with two unknowns, however, we are not so fortunate, and if we increase the number of unknowns to three or more we have practically no good applications in any of our books. As a result we find ourselves resorting to the mere puzzle, to some absurd hypothetical case, To be sure we can clothe the problem in concrete language, as in finding the temperature of which the number of degrees Fahrenheit is 5 times the number centigrade, but such problems do not seem genuine, and really are not so. About the best class of problems of this kind at present available is that relating to the mixing of metals or of solutions, but the field is soon exhausted.

In the matter of quadratics we are still more troubled to find 
genuine applications. Physical questions, like the well known problem of the point of equal illumination of two lights and certain problems relating to moving bodies, help us a little. They usually fail, however, because they involve technicalities beyond the knowledge of the pupil. We therefore find ourselves today with practically no good applications in quadratics.

I have now laid before you the general issue. Let me recapitulate:

I. If we can secure genuine, vital problems of the day to illustrate the various chapters of algebra, we shall gain in the interest, and we shall at the same time enhance the practical value of the subject without detracting from the educational value. This has been done in arithmetic, and it may be hoped for in algebra.

2. In certain lines we can find plenty of practical problems, although text-book makers have not as yet availed themselves of this material. These lines are notably the study of the formula, probably the most practical part of all algebra, and the linear equation with one unknown which ranks a close second in the matter of usability. To these may be added the negative number, and the graph which is so closely connected with it. The algebraic graph, however, is not of so great practical importance as is generally assumed. There may also be added the study of ratio in its largest sense, and the complex number.

3. In the work in simultaneous equations and in quadratics we have brought together only a very small number of good practical applications. It is, therefore, to this field of work that I invite your particular attention. I do not believe that we should give up the matter and say, "It is hopeless," "There are no such applications," "What is the use of bothering with the matter so long as the examining bodies remain asleep to the issue?" Just as some of our best teachers have discovered of late a wide range of practical and easily understood formulas, notably in artisans' journals and handbooks; just as a number of illustrations of what was once so puzzling, the negative number, have been discovered; just as the linear equation has of late come to be used extensively in throwing light upon many involved problems of arithmetic, so I have faith that we shall yet find genuine applications for our simultaneous equations and quadratics. It is worth much for us to get together like this and face the issue. It is helpful to clear the atmosphere and see where we stand. We can never solve a problem until we know what it is, and if you 
and I know the goal we may, at least by our sympathy, assist others in attaining it.

I know very well that this suggestion will stimulate some to be on the lookout for genuine applications; that it will have an almost equal value of making a larger number sympathetic with educational advance; but that it will be entirely understood by a small minority. For if it be said that this is an appeal for utilitarian mathematics as against cultural, I have lamentably failed in presenting my case. My appeal here, as in arithmetic, is simply this: Let us cast away pretence and sham in our applied problems; let us have them stand on their merits as puzzles, like the number guessing, as interesting inheritances like the cistern pipes and the couriers, or as real and usable applications taken from the commercial, the scientific, or the social life of today. Let us neglect no necessary abstract work; let us drill upon processes until they become mechanical; but let us make the subject more interesting by honest applications, more valuable by a study of real conditions, more inspiring by furnishing a key to new chambers in the quantitative structure through which we pass. Above all, let us not despair of doing all this, rather taking hope at the success in already finding applications not thought of only a few years ago, and stimulating by our sympathetic interest all who are laboring with honest purpose to improve our algebraic teaching, to rejuvenate this the third oldest of the mathematical sciences, and to make attractive a subject which has of late become rather the most gloomy of the antechambers through which the student passes to reach the vital, progressive, pure mathematics that lies beyond. 